\title{
Penerapan Metode Algoritma $K$-Means untuk Menentukan Pemberian Reward terhadap Pelanggan PT. Telkom Kandatel Bone
}

\author{
MUH. RIFKY PRANANDA ${ }^{1}$ RD. NURAINI SITI FATHONAH², \\ NISA HANUM HARANI ${ }^{3}$
}

1,2,3Politeknik Pos Indonesia, Indonesia

Email: nuraini@poltekpos.ac.id

Received 03 September 2021 | Revised 24 Oktober 2021 | Accepted 25 Oktober 2021

\begin{abstract}
ABSTRAK
Meningkatnya pertumbuhan industri menjadikan perusahaan bersaing mempertahankan pelanggannya. Persaingan di dunia industri memacu perusahaan untuk mencari cara agar penjualan meningkat disertai loyalitas pelanggannya. Pemberian reward merupakan salah satu piliha yang bisa dilakukan oleh perusahaan. Penelitian ini dirancang dengan menggunakan metode minmax dalam penyetaraan nilai atribut. Untuk proses clustering digunakan teknik pengelompokan $k$-means sebagai penentu pelanggan penerima reward. Sejumlah 10 sampel data pelanggan telah diujikan. Hasil dari metode algoritma $k$-means adalah 2 dari 10 pelanggan dinyatakan layak menerima reward, 4 pelanggan kurang layak mendapatkan reward, dan 4 pelanggan tidak layak mendapatkan reward. Hasil penelitian ini dapat membantu perusahaan dalam pemilihan pelanggan terbaik penerima reward dan diharapkan akan mampu meningkatkan loyalitas pelanggan.
\end{abstract}

Kata kunci: Pelanggan, Data, K-Means, Clustering, Minmax, Reward

\section{ABSTRACT}

The increasing growth of the industry makes companies compete to retain their customers. Competition in the industrial world spurred companies to look for ways to increase sales with customer loyalty. Giving rewards is one of the choices that can be made by the company. This study was designed using the minmax value method in equalizing attributes. For the clustering process, the $k$ means grouping technique is used as a determinant of reward recipient customers. A total of 10 samples of customer data have been tested. The results of the k-means algorithm method are 2 out of 10 customers who are declared eligible to receive rewards, 4 customers are less deserving of rewards, and 4 customers are not eligible for rewards. The results of this study can help companies in selecting the best customers who receive rewards and is expected to increase customer loyalty.

Keywords: Customer, Data, K-Means, Clustering, Minmax, Reward 
Penerapan Metode Algoritma K-Means untuk Menentukan Pemberian Reward Terhadap Pelanggan PT.Telkom Kandatel Bone

\section{PENDAHULUAN}

Kabupaten Bone adalah kabupaten terbesar di Provinsi Sulawesi Selatan dikarenakan kondisi geografisnya yang luas. Karakter masyarakat Bone juga sudah modern sehingga mereka mudah menerima hal baru termasuk kemajuan teknologi komunikasi. Begitu pesatnya perkembangan teknologi di kabupaten ini bisa dilihat dari jumlah pengguna produk yang dijual oleh PT. Telkom sudah mencapai 4.324 pengguna.

PT. Telekomunikasi Indonesia (PT. Telkom) sudah dikenal sebagai perusahaan penyedia jasa dan jaringan komunikasi yang lengkap (full service and network provider) terbesar di Indonesia. PT. Telkom menyediakan jasa telepon tetap kabel, jasa telepon tetap nirkabel dan internet serta jasa multimedia lainnya (Ulkhaq, et al., 2017). Telkom Bone belum memiliki sebuah link website, apa yang dilihat via browser (Josi,2017), yang khusus sehingga info jasa dan produk dapat diakses pelanggan melalui sosial media.

PT. Telkom, sama seperti perusahaan lainnya sebagai contoh Bank Rakyat Indonesia (BRI), bersaing mempertahankan pelanggan dan berupaya meningkatkan penjualan. Ada pendapat pelanggan merupakan sumber keuntungan dan kehidupan bagi perusahaan (Putri, et al, 2019). Adalah kondisi yang wajar jika konsumen beralih ke penyedia jasa lain sehingga persaingan antar perusahaan menjadi ketat. Namun perpindahan pelanggan dapat dicegah. Untuk pelanggan setia, Telkom dapat memberikan reward mengingat reward merupakan bentuk penghargaan yang diberikan, baik oleh dan dari perorangan ataupun suatu instansi. Biasanya bentuk reward adalah dalam bentuk benda atau ucapan (Windarto, 2017). Telkom Bone juga mengadakan pemilihan pelanggan penerima reward dengan maksud meningkatkan penjualan dan loyalitas pelanggan. Program yang diadakan oleh PT. Telkom Kandatel Bone ini juga bertujuan pencapaian perencanaan penjualan.

Penilaian untuk pelanggan didasarkan besarnya kontribusi pelanggan tersebut, sehingga masing-masing pelanggan mempunyai nilai yang berbeda bagi perusahaan. Semakin besar kontribusi yang diberikan pelanggan maka semakin besar keuntungan yang diperoleh perusahaan dan sebaliknya (Kartika \& Putri, 2020).

Namun, permasalahan yang terjadi saat ini adalah perusahaan mengalami kesulitan dalam menentukan pelanggan yang pantas mendapatkan penghargaan berdasarkan transaksi pembelian (Muningsih \& Sri, 2018). Selama ini sistem penentuannya dilakukan secara manual dan hasilnya tidak akurat. Untuk mengoptimalkan penentuan pemberian reward dibutuhkan suatu metode sehingga para pelanggan terbagi menjadi beberapa klaster atau kelompok. Perolehan klaster akan menjadi informasi yang dibutuhkan pengguna kebijakan pada saat pengambilan keputusan (Khomarudin, et al., 2016).

Penelitian ini dilakukan untuk membantu perusahaan dalam menentukan penerima reward terhadap pelanggan yang diadakan setiap 6 bulan sekali. Penelitian ini dirancang dengan menggunakan metode minmax dalam penyetaraan nilai atribut dan menggunakan clustering dengan teknik pengelompokan $k$-means dalam menentukan reward kepada pelanggan.

Algoritma $k$-means adalah metode pengelompokan atau clustering yang familiar yang mengenali klaster dengan cara meminimalisasi kesalahan pengklusteran (Wang, et al., 2016) 
Terdapat parameter-parameter yang telah ditentukan dalam penerapan algoritma $k$-means sehingga penelitian ini terbantu dalam proses pengelompokannya. Parameter yang ditentukan adalah Lama berlangganan, Jumlah pembelian dalam 6 bulan terakhir, dan Biaya belanja atau Total Harga, sehingga akan dihasilkan informasi pelanggan calon penerima reward berdasarkan hasil cluster. Berikut adalah tujuan penelitian ini :

a. Untuk meningkatkan minat pelanggan untuk tetap bertahan menggunakan barang atau jasa Telkom dan dapat menjaga loyalitas pelanggan, karena reward menjadi pengalih pelanggan dari wirausaha lain (Apriana, et al., 2018).

b. Untuk menerapkan algoritma $k$-means yang mengklaster data pelanggan calon penerima reward. Sebagai algoritma populer, K-Means dipilih karena sederhana (Celebi, et al., 2013). Proses clusteringnya ada 2 yaitu proses untuk mendeteksi lokasi pusat klasterdan proses untuk mencari anggota setiap klaster(Agustin, et al., 2015).

\section{METODE}

Berikut adalah tahapan metode penelitian dalam penelitian ini :

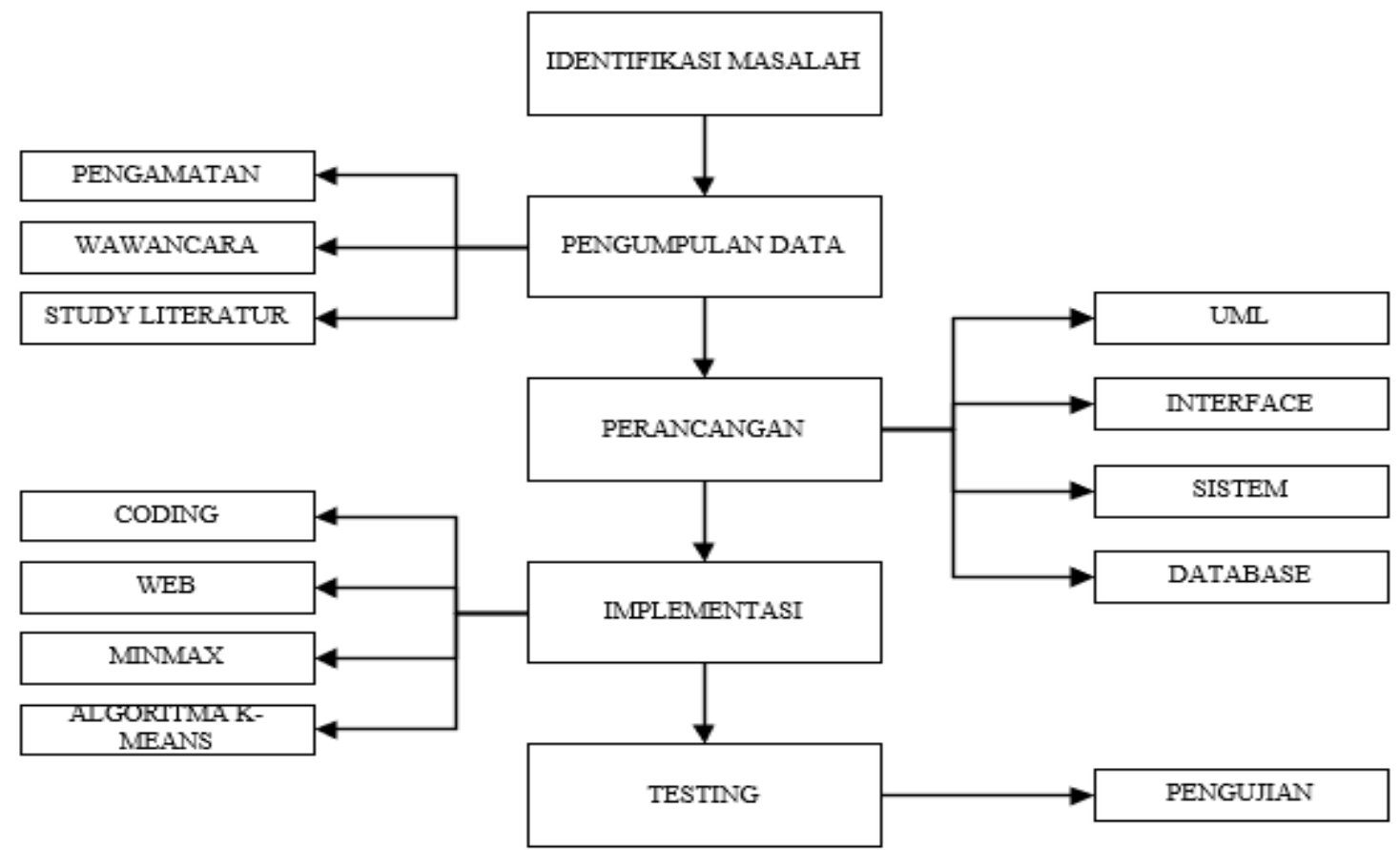

Gambar 1. Alur metodologi penelitian

\subsection{Metode Minmax}

Sebagai metode normalisasi, Minmax melakukan transformasi linier data asli (Lutfia, et al., 2020), dengan kata lain Minmax memproses pembuatan variabel-variabel yang rentang nilainya sama. Secara seimbang data yang ada diubah dari 0 sampai dengan 1, yang meskipun prosesnya kompleks isi data tidak berubah sehingga lebih mudah diolah (Wimmer, 2018). Data yang akan diubah akan memiliki range nilai dari 0 sampai 1 sehingga nilai yang dihasilkan bisa setara dengan nilai yang lain. Adapun rumus dari metode minmax sebagai berikut :

$$
X=\frac{X-X \min }{X \max -X \min }
$$


Cara kerja dari rumus metode Minmax yaitu nilai setiap fitur dikurangi nilai minimum fitur tersebut, selanjutnya dibagi nilai maksimum dikurangi nilai minimum dari fitur tersebut.

\subsection{Metode Algoritma $K$-Means}

K-Means termasuk metode analisis klaster unsupervised machine learning algorithms (Ramadhani, 2019). Tujuan metode ini adalah untuk memecah objek menjadi k klasterlalu diamati. Setiap objek klaster diperoleh melalui rata-rata terdekat (Salam, 2017). K-Means disebut algoritma evolusi karena metode operasi $K$-Means memiliki artian yang sama dengan nama algoritmanya (Kamila, et al., 2019). K, menurut Eko Junaidi Salam, sebagai angka positif. $K$ menyatakan jumlah grup/kluster/partisi terhadap objek. Pengelompokan data dilakukan dengan mencari nilai jarak minimum antara data dan nilai centroid yang telah ditentukan baik secara acak maupun dengan cara menetapkan terlebih dahulu Initial Set of Centroids. Dengan cara ini nilai centroid (nilai rata-rata aritmetik dari sebuah bentuk objek dari seluruh titik dalam objek tersebut) ditentukan berdasarkan $K$ object yang berurutan. $K$ merupakan parameter input yang diamati dalam kelompok. Pada setiap pengamatan, data ditetapkan berdasarkan pengamatan nilai rata-rata cluster. Pada proses awalnya nilai ratarata klaster dihitung secara berulang (Kamila, et al. 2019). Tahap-tahap K-Means Clustering adalah sebagai berikut :

1. Penyeleksian secara acak nilai k untuk dijadikan pusat Klaster awal.

2. Pembagian setiap data dalam dataset ke dalam kelompok-kelompok Klaster antara setiap titik dan pusat cluster. Pembagian didapatkan berdasarkan pada jarak Euclidean.

Rumus perhitungan Euclidean Distance ditunjukkan pada persamaan berikut :

$$
\mathrm{d}=\sqrt{\left(x_{1}-x_{2}\right)^{2}+\left(y_{1}-y_{2}\right)^{2}}
$$

dengan :

$\mathrm{d}=$ jarak dari data ke pusat Klaster

$\mathrm{x}_{1}=$ nilai Klaster di atribut

$\mathrm{x}_{2}=$ titik centroid Klaster awal

$\mathrm{y}_{1}=$ nilai Klaster pada atribut ke 2

$\mathrm{y}_{2}=$ titik pusat Klaster awal

dimana akar kuadrat dari nilai $\mathrm{x}_{1}-\mathrm{x}_{2}$ kuadrat ditambah dengan hasil nilai $\mathrm{y}_{1}-\mathrm{y}_{2}$ kuadrat.

3. Penghitungan ulang setiap pusat klaster berdasarkan dari nilai rata-rata di Klaster yang diperoleh.

4. Pengulangan langkah 2 dan 3 hingga kelompok tersebut sesuai. Perulangan dapat diartikan secara berbeda karena bergantung pada implementasi, tetapi biasanya proses langkah 2 dan 3 dapat diulangi jika kelompok klaster masih berubah. Proses perulangan akan terhenti jika tidak ada lagi perubahan antar material dalam klaster.

\section{HASIL DAN PEMBAHASAN}

\subsection{Memuat Data}

Dataset adalah hal pertama yang dilakukan untuk mengambil data dari dataset yang digunakan. Pada penelitian ini, penulis mengambil 10 sampel data transaksi pelanggan yang dimuat ditampilkan pada Tabel 1. 
Tabel 1. Dataset

\begin{tabular}{|c|c|l|l|l|l|}
\hline No. & $\begin{array}{c}\text { Id } \\
\text { Pelanggan }\end{array}$ & $\begin{array}{c}\text { Nama } \\
\text { Pelanggan }\end{array}$ & $\begin{array}{c}\text { Lama } \\
\text { Berlangganan }\end{array}$ & $\begin{array}{c}\text { Jumlah Pembelian } \\
\text { dalam } \mathbf{6} \text { Bulan } \\
\text { Terakhir }\end{array}$ & $\begin{array}{c}\text { Biaya Belanja / } \\
\text { Total Harga }\end{array}$ \\
\hline 1 & 4114763352 & Suwandi & 51 bulan & 10 produk & Rp. 3.739 .000 \\
\hline 2 & 4113690349 & Aryana & 16 bulan & 12 produk & Rp. 4.373 .000 \\
\hline 3 & 4118900868 & Muh. Marzuki & 26 bulan & 8 produk & Rp. 2.450 .000 \\
\hline 4 & 4114674038 & $\begin{array}{l}\text { Oktavian } \\
\text { valentino }\end{array}$ & 40 bulan & 6 produk & Rp. $2 \cdot 100.000$ \\
\hline 5 & 4114677238 & Nur azizah $n$ & 11 bulan & 13 produk & Rp. 4.560 .000 \\
\hline 6 & 4118989803 & Muliati & 19 bulan & 9 produk & Rp. 4.050 .000 \\
\hline 7 & 4114832529 & Alamsyah & 50 bulan & 8 produk & Rp. 3.800 .000 \\
\hline 8 & 4120993538 & Ikram & 21 bulan & 7 produk & Rp. 2.450 .000 \\
\hline 9 & 4114670165 & Sofyan & 13 bulan & 11 produk & Rp. 4.250 .000 \\
\hline 10 & 4118993592 & Asbat & 20 bulan & 9 produk & Rp. 2.950 .000 \\
\hline
\end{tabular}

\subsection{Metode Minmax}

Sebelum melanjutkan ke tahapan selanjutnya maka terlebih dahulu dilakukan penyetaraan nilai menggunakan metode minmax dari kolom yang akan menjadi penilaian. Kolom penilaian terdiri dari Lama berlangganan, Jumlah pembelian, dan Biaya belanja. Berikut adalah hasil penyetaraan nilai yang termuat pada Tabel 2 .

Tabel 2. Minmax

\begin{tabular}{|c|c|l|c|c|c|}
\hline No. & $\begin{array}{c}\text { Id } \\
\text { Pelanggan }\end{array}$ & $\begin{array}{c}\text { Nama } \\
\text { Pelanggan }\end{array}$ & $\begin{array}{c}\text { Lama } \\
\text { Berlangganan }\end{array}$ & $\begin{array}{c}\text { Jumlah Pembelian } \\
\text { dalam 6 Bulan } \\
\text { Terakhir }\end{array}$ & $\begin{array}{c}\text { Biaya Belanja / } \\
\text { Total Harga }\end{array}$ \\
\hline 1 & 4114763352 & Suwandi & 0,46 & 0,20 & 0,30 \\
\hline 2 & 4113690349 & Aryana & 0,07 & 0,28 & 0,37 \\
\hline 3 & 4118900868 & Muh. Marzuki & 0,18 & 0,12 & 0,16 \\
\hline 4 & 4114674038 & $\begin{array}{l}\text { Oktavian } \\
\text { valentino }\end{array}$ & 0,33 & 0,04 & 0,12 \\
\hline 5 & 4114677238 & Nur azizah $n$ & 0,01 & 0,32 & 0,40 \\
\hline 6 & 4118989803 & Muliati & 0,10 & 0,16 & 0,34 \\
\hline 7 & 4114832529 & Alamsyah & 0,44 & 0,12 & 0,31 \\
\hline 8 & 4120993538 & Ikram & 0,12 & 0,08 & 0,16 \\
\hline 9 & 4114670165 & Sofyan & 0,03 & 0,24 & 0,36 \\
\hline 10 & 4118993592 & Asbat & 0,11 & 0,16 & 0,22 \\
\hline
\end{tabular}

\subsection{Algoritma $K$-Means}

Setelah dilakukan penyetaraan nilai, maka langkah berikutnya dilakukan pengklasteran menggunakan $k$-means. Dari proses ini akan didapatkan hasil siapa saja yang layak mendapatkan reward sesuai dengan kriteria penilaian. Adapun proses dari algoritma $k$ means sebagai berikut :

\section{a. Mengumpulkan Dataset}

Berikut merupakan tabel dataset dari 10 pelanggan yang penulis jadikan contoh pada simulasi data penerima reward. Hasil data yang terkumpul ini dijadikan sebagai data sampel seperti tersaji di Tabel 3. 
Penerapan Metode Algoritma K-Means untuk Menentukan Pemberian Reward Terhadap Pelanggan PT.Telkom Kandatel Bone

Tabel 3. Data pelanggan

\begin{tabular}{|c|c|c|c|}
\hline Nama Pelanggan & Lama Berlangganan & Jumlah Pembelian & Total Belanja \\
\hline Suwandi & 0,46 & 0,20 & 0,30 \\
\hline Aryana & 0,07 & 0,28 & 0,37 \\
\hline Muh. Marzuki & 0,18 & 0,12 & 0,16 \\
\hline Oktavian valentino & 0,33 & 0,04 & 0,12 \\
\hline Nur azizah $\mathrm{n}$ & 0,01 & 0,32 & 0,40 \\
\hline Muliati & 0,10 & 0,16 & 0,34 \\
\hline Alamsyah & 0,44 & 0,12 & 0,31 \\
\hline Ikram & 0,12 & 0,08 & 0,16 \\
\hline Sofyan & 0,03 & 0,24 & 0,36 \\
\hline Asbat & 0,11 & 0,16 & 0,22 \\
\hline
\end{tabular}

Terlihat ada 3 kriteria penilaian yaitu Lama berlangganan, Jumlah pembelian, dan Total belanja dan terdapat 10 pelanggan. Ke-10 pelanggan tersebut akan dikelompokkan menjadi 3 klaster yaitu :

Klaster $1(\mathrm{C} 1)$

Klaster 2 (C2)

Klaster 3 (C3)

\section{b. Penentuan pusat klaster awal}

Pada tahap ini penulis menetapkan $\mathrm{C}$ pusat klaster awal secara acak untuk menghitung centroid. Untuk pusat klaster awal, penulis memilih data pelanggan bernama Suwandi, Aryana, dan Muh. Marzuki.

Tabel 4. Data Klaster

\begin{tabular}{|c|c|c|c|}
\hline Klaster & \multicolumn{3}{|c|}{ Titik Pusat klaster } \\
\hline Klaster 1 & 0,46 & 0,20 & 0,30 \\
\hline Klaster 2 & 0,07 & 0,28 & 0,37 \\
\hline Klaster 3 & 0,18 & 0,12 & 0,16 \\
\hline
\end{tabular}

\section{c. Perhitungan jarak pusat klaster}

Selanjutnya Euclidian Distance diterapkan pada saat pengalokasian semua objek ke dalam klaster terdekat. Hasilnya adalah jarak minimum objek terhadap centroid.

Berikut hasil dari data yang telah dijumlahkan menggunakan rumus euclidian distance:

\section{d. Pengklasteran data}

Jarak terdekat antara objek dengan centroid dipilih setelah jarak hasil perhitungan dibandingkan. Jarak ini mengindikasikan bahwa suatu objek atau data tadi berada dalam satu kelompok dengan pusat klaster terdekat.

$$
\begin{aligned}
& d(1,1)=\sqrt{(0,46-0,46)^{2}+(0,20-0,20)^{2}+(0,30-0,30)^{2}}=0 \\
& d(1,2)=\sqrt{(0,46-0,07)^{2}+(0,20-0,28)^{2}+(0,30-0,37)^{2}}=0,4042276586 \\
& d(1,3)=\sqrt{(0,46-0,18)^{2}+(0,20-0,12)^{2}+(0,30-0,16)^{2}}=0,3231098884 \\
& d(2,1)=\sqrt{(0,07-0,46)^{2}+(0,28-0,20)^{2}+(0,37-0,30)^{2}}=0,4042276586 \\
& d(2,2)=\sqrt{(0,07-0,07)^{2}+(0,28-0,28)^{2}+(0,37-0,37)^{2}}=0 \\
& d(2,3)=\sqrt{(0,07-0,18)^{2}+(0,28-0,12)^{2}+(0,37-0,16)^{2}}=0,2860069929 \\
& d(3,1)=\sqrt{(0,18-0,46)^{2}+(0,12-0,20)^{2}+(0,16-0,30)^{2}}=0,3231098884 \\
& d(3,2)=\sqrt{(0,18-0,07)^{2}+(0,12-0,28)^{2}+(0,16-0,37)^{2}}=0,2860069929 \\
& d(3,3)=\sqrt{(0,18-0,18)^{2}+(0,12-0,12)^{2}+(0,16-0,16)^{2}}=0
\end{aligned}
$$




$$
\begin{aligned}
& d(4,1)=\sqrt{(0,33-0,46)^{2}+(0,04-0,20)^{2}+(0,12-0,30)^{2}}=0,2736786437 \\
& d(4,2)=\sqrt{(0,33-0,07)^{2}+(0,04-0,28)^{2}+(0,12-0,37)^{2}}=0,4332435804 \\
& d(4,3)=\sqrt{(0,33-0,18)^{2}+(0,04-0,12)^{2}+(0,12-0,16)^{2}}=0,174642492 \\
& d(5,1)=\sqrt{(0,01-0,46)^{2}+(0,32-0,20)^{2}+(0,40-0,30)^{2}}=0,4763402146 \\
& d(5,2)=\sqrt{(0,01-0,07)^{2}+(0,32-0,28)^{2}+(0,40-0,37)^{2}}=0,0781024968 \\
& d(5,3)=\sqrt{(0,01-0,18)^{2}+(0,32-0,12)^{2}+(0,40-0,16)^{2}}=0,3556683849 \\
& d(6,1)=\sqrt{(0,10-0,46)^{2}+(0,16-0,20)^{2}+(0,34-0,30)^{2}}=0,3644173432 \\
& d(6,2)=\sqrt{(0,10-0,07)^{2}+(0,16-0,28)^{2}+(0,34-0,37)^{2}}=0,1272792206 \\
& d(6,3)=\sqrt{(0,10-0,18)^{2}+(0,16-0,12)^{2}+(0,34-0,16)^{2}}=0,2009975124 \\
& d(7,1)=\sqrt{(0,44-0,46)^{2}+(0,12-0,20)^{2}+(0,31-0,30)^{2}}=0,0830662386 \\
& d(7,2)=\sqrt{(0,44-0,07)^{2}+(0,12-0,28)^{2}+(0,31-0,37)^{2}}=0,4075536774 \\
& d(7,3)=\sqrt{(0,44-0,18)^{2}+(0,12-0,12)^{2}+(0,31-0,16)^{2}}=0,3001666204 \\
& d(8,1)=\sqrt{(0,12-0,46)^{2}+(0,08-0,20)^{2}+(0,16-0,30)^{2}}=0,3867815921 \\
& d(8,2)=\sqrt{(0,12-0,07)^{2}+(0,08-0,28)^{2}+(0,16-0,37)^{2}}=0,2942787794 \\
& d(8,3)=\sqrt{(0,12-0,18)^{2}+(0,08-0,12)^{2}+(0,16-0,16)^{2}}=0,0721110255 \\
& d(9,1)=\sqrt{(0,03-0,46)^{2}+(0,24-0,20)^{2}+(0,36-0,30)^{2}}=0,4360045871 \\
& d(9,2)=\sqrt{(0,03-0,07)^{2}+(0,24-0,28)^{2}+(0,36-0,37)^{2}}=0,0574456265 \\
& d(9,3)=\sqrt{(0,03-0,18)^{2}+(0,24-0,12)^{2}+(0,36-0,16)^{2}}=0,2773084925 \\
& d(10,1)=\sqrt{(0,11-0,46)^{2}+(0,16-0,20)^{2}+(0,22-0,30)^{2}}=0,3612478374 \\
& d(10,2)=\sqrt{(0,11-0,07)^{2}+(0,16-0,28)^{2}+(0,22-0,37)^{2}}=0,1962141687 \\
& d(10,3)=\sqrt{(0,11-0,18)^{2}+(0,16-0,12)^{2}+(0,22-0,16)^{2}}=0,1004987562
\end{aligned}
$$

Tabel 5. Jarak pusat cluster

\begin{tabular}{|c|c|c|c|c|}
\hline \multirow{2}{*}{ Nama Pelanggan } & \multicolumn{3}{|c|}{ Jarak ke Cluster } & Hasil \\
\cline { 2 - 5 } & C1 & C2 & 0,3231098884 & 1 \\
\hline Suwandi & 0 & 0,4042276586 & 0,2860069929 & 2 \\
\hline Aryana & 0,4042276586 & 0 & 0 & 3 \\
\hline Muh. Marzuki & 0,3231098884 & 0,2860069929 & 0,174642492 & 3 \\
\hline Oktavian Valentino & 0,2736786437 & 0,4332435804 & 0,3556683849 & 2 \\
\hline Nur Azizah & 0,4763402146 & 0,0781024968 & 0,2009975124 & 2 \\
\hline Muliati & 0,3644173432 & 0,1272792206 & 0,3001666204 & 1 \\
\hline Alamsyah & 0,0830662386 & 0,4075536774 & 0,0721110255 & 3 \\
\hline Ikram & 0,3867815921 & 0,2942787794 & 0,2773084925 & 2 \\
\hline Sofyan & 0,4360045871 & 0,0574456265 & 0,1004987562 & 3 \\
\hline Asbar & 0,3612478374 & 0,1962141687 & \\
\hline
\end{tabular}

\section{Iterasi 1}

\section{e. Penentuan pusat Klaster baru}

Jika anggota tiap klaster sudah diketahui, pusat klaster baru dihitung berdasarkan data anggota tiap-tiap klaster sesuai dengan rumus pusat anggota klaster. 
Klaster baru tersebut didapat dari rumus $=$ nilai hasil /banyak hasil.

Klaster 1 (Lama berlangganan) $=(0,46+0,44) / 2=0,45$

Klaster 1 (Jumlah pembelian) $=(0,20+0,12) / 2=0,16$

Klaster 1 (Total belanja) $=(0,30+0,31) / 2=0,30$

Klaster 2 (Lama berlangganan) $=(0,07+0,01+0,10+0,03) / 4=0,05$

Klaster 2 (Jumlah pembelian) $=(0,28+0,32+0,16+0,24) / 4=0,25$

Klaster 2 (Total belanja) $=(0,37+0,40+0,34+0,36) / 4=0,37$

Klaster 3 (Lama berlangganan) $=(0,18+0,33+0,12+0,11) / 4=0,18$

Klaster 3 (Jumlah pembelian) $=(0,12+0,04+0,08+0,16) / 4=0,10$

Klaster 3 (Total belanja $)=(0,16+0,12+0,16+0,22) / 4=0,16$

\section{Tabel 6. Jarak pusat klaster baru}

\begin{tabular}{|c|c|c|c|}
\hline Klaster & \multicolumn{3}{|c|}{ Titik Pusat } \\
& Klaster baru \\
\hline Klaster1 & 0,45 & 0,16 & 0,30 \\
\hline Klaster2 & 0,05 & 0,25 & 0,37 \\
\hline Klaster3 & 0,18 & 0,10 & 0,16 \\
\hline
\end{tabular}

Selanjutnya, tahap 3 diulang sampai titik pusat dari setiap klaster tidak berubah. Jika titik pusat ada yang berubah, maka tahap 3 diulang sampai titik pusat dari setiap klaster tidak berubah.

Hasil perulangan tahap 3 yaitu :

Tabel 7. Jarak pusat klaster baru

\begin{tabular}{|c|c|c|c|c|}
\hline \multirow{2}{*}{ Nama Pelanggan } & \multicolumn{3}{|c|}{ Jarak ke Cluster } & Hasil \\
\cline { 2 - 5 } & C1 & C2 & C3 & \\
\hline Suwandi & 0,0412310563 & 0,4189272013 & 0,3286335345 & 1 \\
\hline Aryana & 0,4045985665 & 0,0360555128 & 0,2976575213 & 2 \\
\hline Muh. Marzuki & 0,306757233 & 0,2791057147 & 0,02 & 3 \\
\hline Oktavian Valentino & 0,2473863375 & 0,4301162634 & 0,1664331698 & 3 \\
\hline Nur Azizah & 0,4787483681 & 0,0860232527 & 0,3672873534 & 2 \\
\hline Muliati & 0,3522782991 & 0,1072380529 & 0,2059126028 & 2 \\
\hline Alamsyah & 0,0424264069 & 0,4154515616 & 0,3008321791 & 1 \\
\hline Ikram & 0,3672873534 & 0,2791057147 & 0,0632455532 & 3 \\
\hline Sofyan & 0,4317406629 & 0,0244948974 & 0,2865309756 & 2 \\
\hline Asbar & 0,3492849839 & 0,1849324201 & 0,11 & 3 \\
\hline
\end{tabular}

\section{Iterasi 2}

Berdasarkan perhitungan yang telah dilakukan pada Iterasi ke 2, titik pusat klaster tidak ada yang berubah dari Iterasi 1 . Maka, tidak perlu dilakukan perulangan lagi. 
Berikut hasil pengolahan data klaster pelanggan:

Tabel 8. Hasil

\begin{tabular}{|c|c|c|c|c|}
\hline Nama Pelanggan & Lama Berlangganan & Jumlah Pembelian & Total Belanja & Hasil \\
\hline Suwandi & 0,46 & 0,20 & 0,30 & C1 \\
\hline Aryana & 0,07 & 0,28 & 0,37 & C2 \\
\hline Muh. Marzuki & 0,18 & 0,12 & 0,16 & C3 \\
\hline Oktavian Valentino & 0,33 & 0,04 & 0,12 & C3 \\
\hline Nur Azizah & 0,01 & 0,32 & 0,40 & C2 \\
\hline Muliati & 0,10 & 0,16 & 0,34 & C2 \\
\hline Alamsyah & 0,44 & 0,12 & 0,31 & C1 \\
\hline Ikram & 0,12 & 0,08 & 0,16 & C3 \\
\hline Sofyan & 0,03 & 0,24 & 0,36 & C2 \\
\hline Asbar & 0,11 & 0,16 & 0,22 & C3 \\
\hline
\end{tabular}

Berdasarkan hasil perhitungan pada tabel di atas, pelanggan yang bernama Suwandi dan Alamsyah berada di klaster 1; Valentino, Ikram, dan Asbar berada pada klaster 3 sesuai dengan hasil dari perhitungan yang menunjukkan bahwa hasil yang terkecil atau terdekat berada di klaster 3 dan tidak layak mendapatkan reward.

Jadi dapat disimpulkan bahwa metode algoritma $K$-Means clustering dapat membantu penyelesaian masalah penentuan penerima reward dari perhitungan yang menunjukkan bahwa hasil yang terkecil atau terdekat berada di klaster 1 sehingga layak mendapatkan reward. Adapun pelanggan yang bernama Aryana, Nur Azizah, Muliati, dan Sofyan berada pada klaster 2 sesuai dengan hasil dari perhitungan yang menunjukkan bahwa hasil yang terkecil atau terdekat berada di klaster 2 sehingga kurang layak mendapatkan reward. Sedangkan pelanggan yang bernama Muh, Marzuki, Oktavian val pelanggan PT. Telkom Kandatel Bone.

\section{KESIMPULAN}

Kesimpulan penelitian yang berjudul Penerapan Algoritma $K$-Means untuk Menentukan Pemberian Reward Terhadap Pelanggan PT. Telkom Kandatel Bone ini adalah sebagai berikut :

1. Diadakannya pemberian reward terhadap pelanggan diharapkan akan lebih meningkatkan kepuasan pelanggan sehingga loyalitas pelanggan dapat terjaga dengan baik.

2. Metode algoritma $k$-means clustering dapat membantu pemilihan pelanggan penerima reward berdasarkan kriteria-kriteria penilaian yang ditetapkan. 


\section{UCAPAN TERIMA KASIH}

Penulis mengucapkan terima kasih kepada semua pihak yang telah mendukung penelitian ini. Terutama kepada Prodi Diploma 4 Teknik Informatika Politeknik Pos Indonesia, dan dosen pembimbing yang telah memberikan bimbingan sehingga penelitian ini terlaksana dengan baik.

\section{DAFTAR RUJUKAN}

Agustin, Fenty Eka M. (2015). "Implementasi Algoritma K-Means Untuk Menentukan Kelompok Pengayaan Materi Mata Pelajaran Ujian Nasional (Studi Kasus: Smp Negeri 101 Jakarta)." Jurnal Teknik Informatika.

Apriana, Veti. (2018). "Penerapan Metode Profile Matching Untuk Menentukan Pemberian Reward Terhadap Pelanggan Pada Bisnis Ritel." Jurnal Pilar Nusa Mandiri, 14(1), 117-122.

Celebi, et. al. (2013). "A comparative study of efficient initialization methods for the k-means clustering algorithm." Expert systems with applications, 4O(1), 200-210.

Josi, Ahmat. (2017). "Penerapan Metode Prototiping Dalam Pembangunan Website Desa (Studi Kasus Desa Sugihan Kecamatan Rambang)." Jurnal Teknologi Informasi.

Kartika, Putri. (2020). Pemberian Reward Kepada Pelanggan Terbaik Menggunakan Metode Maut Pada Toko Kurnia/Dadang Tanjungbalai. Diss. Stmik Royal Kisaran.

Kamila, Insanul, Ulya Khairunnisa, and Mustakim Mustakim. (2019). "Perbandingan Algoritma K-Means dan K-Medoids untuk Pengelompokan Data Transaksi Bongkar Muat di Provinsi Riau." Jurnal IImiah Rekayasa dan Manajemen Sistem Informasi, 119-125.

Khomarudin, Agus Nur. (2016). "Teknik Data Mining: Algoritma K-Means Clustering." Ilmu Komputer.

Lutfia, Afifah. (2020). Ilmudatapy. Retrieved from https://ilmudatapy.com/metodenormalisasi-data/

Muningsih, Elly, and Sri Kiswati. (2018). "Sistem aplikasi berbasis optimasi metode elbow untuk penentuan clustering pelanggan." Joutica 3.1, 117-124.

Ramadhani, Rizky Desi (2019). Memahami K-Means Clustering dengan R. Retrieved from https://medium.com/@16611129/belajarbersama-kides-episode-2-cd51d0bfd121

Salam, Eko Junaidi. (2017). K-means-clustering-algorithm. Retrieved from https://ekojunaidisalam.com/2017/02/09/ 
Ulkhaq, M. Mujiya, and Monalisa Putri Br Barus. (2017). "Analisis Kepuasan Pelanggan dengan Menggunakan SERVQUAL: Studi Kasus Layanan IndiHome PT. Telekomunikasi Indonesia, Tbk, Regional 1 Sumatera." Jurnal Sistem dan Manajemen Industri, 61-67.

Windarto, A. P. (2017). "Implementasi Metode Topsis Dan Saw Dalam Memberikan Reward Pelanggan". Kumpulan jurnaL Ilmu Komputer.

Wang, Xiaoyan \& Bai, Yanping, (2016). A Modified MinMax K-Means Algorithm Based on PSO. Computational Intelligence and Neuroscience.

Wimmer, H. (2018). Effects of Normalization Techniques on Logistics Regression in Data Science. Proceedings of the Conference on Information Systems Applied Research, (pp. 1-9). 